\title{
PerCursos
}

\section{Dentro, fora, antes ou depois? - A política espaço-temporal de Notícias da América, de Paulo Nazareth}

\begin{abstract}
Resumo
Este artigo investiga a performance Notícias da América, do artista Paulo Nazareth. Nela são identificadas discussões (e ações) que manejam uma pluralidade de passados (ancestrais, coloniais) e, ao mesmo tempo, abrem perspectivas relacionais, característica típica da arte contemporânea desde os anos 1960. Na performance, à medida que Nazareth se desloca por cidades latino-americanas, as imagens e os discursos produzidos forjam um espaço comum entre ele próprio, seus interlocutores e a paisagem. Simultaneamente, emerge uma temporalidade múltipla em que subjetividades periféricas se tornam visíveis. É também a partir dessa relação espaço-temporal que outras de suas produções artísticas (como a série Aqui é arte) podem ser desdobradas.
\end{abstract}

Palavras-chave: arte latino-americana; performance; Paulo Nazareth; temporalidades híbridas; pós-utopico.

\author{
Natalie Lima \\ Doutora em Literatura, Cultura e \\ Contemporaneidade pela \\ Pontifícia Universidade Católica \\ do Rio de Janeiro- PUC-Rio. Pós- \\ doutoranda no Instituto de \\ Letras da Universidade Federal \\ Fluminense - UFF. \\ Brasil \\ nataliearaujolima@gmail.com \\ orcid.org/0000-0002-2687-4684
}

\section{Para citar este artigo:}

LIMA, Natalie. Dentro, fora, antes ou depois? - A política espaço-temporal de Notícias da América, de Paulo Nazareth. PerCursos, Florianópolis, v. 22, n.50, p. 292 - 318, set./dez. 2021.

DOI: $10.5965 / 1984724622502021292$

http://dx.doi.org/10.5965/1984724622502021292 


\title{
Inside, outside, before or after? - The space-time politics of Notícias da América, by Paulo Nazareth
}

\begin{abstract}
This article investigates the performance Notícias da América, by the artist Paulo Nazareth. It identifies discussions (and actions) that handle a plurality of pasts (ancestral, colonial) and, at the same time, open relational perspectives - a typical feature of contemporary art since the $1960 \mathrm{~s}$. In that performance, as Nazareth moves through Latin American cities, the images and discourses produced forge a common space between himself, his interlocutors and the landscape. Simultaneously, a multiple temporality emerges in which peripheral subjectivities become visible. It is also from this space-time relationship that other of his artistic productions (such as the series Aqui é arte) can be unfolded.
\end{abstract}

Keywords: latin-american art; performance; Paulo Nazareth; hybrid temporalities; post-utopian. 


\section{Um presente a contrapelo}

Nos últimos anos, artistas e escritores latino-americanos têm tematizado o futuro e suas implicações no imaginário social a partir de uma visada complexa. ${ }^{1}$ Para tanto, via de regra partem do presente a fim de romper com uma noção diacrônica do tempo e investir na dimensão espacial durante a abordagem de materiais e temas. Notícias da América, do mineiro Paulo Nazareth, é o trabalho aqui escolhido para abordar a questão porque produz uma intervenção no tecido social por onde o artista literalmente transita, evidenciando a dimensão espaço-temporal dos encontros que ele trava e destacando o máximo possível as contingências geográficas em que os mesmos ocorrem. Realizada durante os anos de 2011 e 2012, a performance de longa duração consistiu em se deslocar a pé e de ônibus por toda a América Latina, tendo como ponto de chegada a cidade de Nova York e o rio Hudson, onde o artista lavou os pés pela primeira vez após muitos meses de viagem. Nazareth partiu da cidade de Governador Valadares, em Minas Gerais, e passou por cidades de diversos países sul-americanos, caribenhos e também pelo México, onde atravessou a fronteira em direção aos Estados Unidos. Ao voltar dos EUA, foi até Miami a fim de participar da feira Art Basel.

O registro de sua performance de longa duração se deu a partir de diferentes plataformas: o diário on-line que manteve pelo endereço eletrônico <http://latinamericanotice.blogspot.com>, as fotografias que fez (muitas delas presentes no site), os desenhos que duplicam notícias de jornal, projeto que batiza de Imagens que já existem no mundo, a instalação Banana Market/Art Market, uma kombi lotada de bananas que expôs na Art Basel, bem como as pequenas performances e/ou projetos como os registros de "Cara de índio", dos quais também falaremos neste artigo. Em todos esses desdobramentos, como se verá, o artista critica a ideia moderna de futuro

\footnotetext{
${ }^{1}$ Seja realizando uma crítica à ditadura do tempo presente, em sintonia com o que diz o historiador francês François Hartog (2013), seja desviando-se do imaginário distópico forjado por tantas ficções literárias e audiovisuais, trabalhos como o filme Navio-Ovni, de Fabiana Ex-Souza, as instalações Direito à preguiça, de Nuno Ramos, e El hombre con el hacha, da argentina Liliana Porter, a performance de longa duração Notícias da América, de Paulo Nazareth, abordada neste artigo, bem como o romance 2666, do chileno Roberto Bolaño, o poema longo "Prólogo canino-operístico", de Carlito Azevedo, a novela Cães heróis Tratado sobre o futuro da América Latina visto através de um homem imóvel e seus trinta pastores belgas malinois, do peruano-mexicano Mario Bellatin, e o romance Runa, do argentino Rodolfo Fogwill, para citar alguns casos nas artes visuais e na literatura, apresentam uma ideia de futuro que problematiza a fé moderna e modernista sobre tal temporalidade, tanto do ponto de vista político quanto estético.
} 
denunciando, em sua viagem, um projeto falido: a cada lugar para onde Nazareth se desloca, as imagens e os encontros com moradores e viajantes sugerem uma América Latina marcada pela ruína, pela catástrofe, mas também por modos de vida periféricos e inventivos, resultado de séculos de espoliação, por um lado, e de resistência, por outro. Tal crítica a uma concepção moderna de futuro e seus resultados em solo latinoamericano têm como pano de fundo um ataque ao mito fundacional da versão eurocêntrica da modernidade. Nesse mito, como afirma Aníbal Quijano (2005, p. 116) em “Colonialidade do poder, eurocentrismo e América Latina”, “a ideia do estado de natureza como ponto de partida do curso civilizatório cuja culminação é a civilização europeia ou ocidental" é o que dá base discursiva para uma "perspectiva evolucionista, de movimento e de mudança unilinear e unidirecional da história humana". Numa estrutura social racializada como a que nos foi imposta pela modernidade, mestiços, descendentes de africanos e indígenas, bem como as terras que ocupamos e os modos de vida que praticamos, tudo isso corresponderia a um estado de natureza - ideia que se desdobra, metonimicamente, num imaginário sobre o primitivo, o periférico e até sobre a própria América Latina com relação ao continente americano em sua totalidade. Os Estados Unidos e o Canadá, por sua vez, seriam as partes mais “ocidentais" da América consequentemente, o ponto máximo de evolução a que o continente pode aspirar; são seu centro. A noção "colonialidade do poder”, aliás, pode ser entendida, conforme diz Walter Mignolo (2005, p. 33), como aquilo que organizou e continua organizando a diferença colonial, "a periferia como natureza". No contexto latino-americano, a naturalização do "subdesenvolvimento" tem suas raízes, e sua permanência, na colonialidade do poder atualizada. A “América Latina é hoje, na ordem mundial, produto da diferença colonial e de sua rearticulação sobre a diferença imperial que se gesta a partir do século XVII na Europa do Norte e se restitui na emergência de um país neocolonial como os Estados Unidos" (MIGNOLO, 2005, p. 46).

Mais como provocação sígnica do que como ironia, a relação espaço/tempo que se estabelece na performance de Paulo Nazareth reproduz o raciocínio da diferença colonial não para reafirmá-lo, mas para mostrar seu delírio: o ponto de chegada, a "América" dos Estados Unidos, a parte mais ocidental e branca do continente americano, está 
necessariamente no futuro por ser o destino final do viajante, por ser o topos aonde chega o artista após ter passado por cidades latino-americanas onde se nota a presença dos povos originários, por descendentes de africanos, bem como por subjetividades marcadas pelos discursos em torno da mestiçagem. Mas é no encontro com esses sujeitos e territórios que a performance de longa duração (incluídos aí seus desdobramentos) ganha, literalmente, cara e corpo, ou seja, que ela se potencializa.

A partir de uma perspectiva territorial e relacional no tempo presente, a crítica ao futuro, temporalidade moderna (e modernista) por excelência, aparece então: documentando as inúmeras paradas e encontros ocorridos durante o trajeto feito a pé e de ônibus de Minas Gerais até os Estados Unidos, Nazareth resgata histórias coletivas que teimam em sobreviver em pessoas comuns e suas imagens; ${ }^{2}$ retira a performance do espaço autônomo do museu (ao qual ela nunca pertenceu de fato); inscreve, com o próprio corpo, uma poética do deslocamento e, por fim, lava os pés, sujos de tanto andar pelas terras latinas, no rio Hudson, em Nova York, partindo depois para Miami a fim de participar da Art Basel - na qual, aliás, foi barrado pelo segurança local devido à sua aparência.

Especialmente no que tange aos encontros com as "pessoas comuns", vale destacar as contribuições escriturais de dois guatemaltecos, os irmãos Edgar e Pedro Calel (reproduzidas no livro Paulo Nazareth - Arte contemporânea LTDA., suas cartas funcionam como documentos que atestam o envolvimento do artista mineiro com os hermanos latino-americanos). Edgar Calel é um artista visual que conhece Nazareth na Nicarágua; Pedro Calel é agricultor, pai de dez filhos, morador da cidade guatemalteca de San Juan Comalapa. De maneiras muito distintas, ambos escrevem cartas-testemunho para e sobre Paulo Nazareth, com quem travaram um convívio familiar - gerando, daí, certas relações de parentesco não co-sanguíneas - durante as semanas em que o brasileiro viveu na Guatemala. Em uma carta bilíngue, Edgar Calel afirma:

\footnotetext{
2 O termo "sobreviver" se apoia nos estudos que Georges Didi-Huberman faz sobre a obra de Aby Warburg e seu conceito de Nachleben. Criado pelo historiador da arte alemão para designar como as fórmulas patéticas que ele identificou nas imagens produzidas na Antiguidade sobreviveram, se conservaram ou tiveram uma "vida posterior", na arte Renascentista, Nachleben é resgatado por Didi-Huberman para se tornar um operador conceitual na recepção das imagens no mundo contemporâneo. Ver A sobrevivência dos vagalumes (2011) e Diante do tempo (2015).
} 
Paulo es un amigo que con su trabajo y con sus palavras nos há dejado jun kaioxi etal en nuestra vida, en nuestra existencia colectiva acá en Comalapa. El viene del sur y camina con sus pies descalzos en las profundidades de las culturas ameríndias... a el le gusta el frijol... le gusta ru sij ichaj. (CALEL, 2012, s/p)

Tanto em espanhol quanto em um dos muitos idiomas indígenas falados na Guatemala, Edgar Calel comenta a performance de Paulo Nazareth amalgamando-a com certas características da personalidade do artista brasileiro e com a consciência de uma existência coletiva que acolhe alguém cujos pés trazem consigo a profundidade das culturas ameríndias. Pedro, por sua vez, em carta escrita de próprio punho, oferece a Paulo Nazareth uma generosidade terrosa - "Quando regreses nuevamente a San Juan Comalapa, probaras nuevamente frijol nuevo" - e uma percepção concreta e lúdica ao lado de um desenho: "Paulo, en este dubujo te estoy recordando que por tu altura te molestava el arborito de limon, algunas veces te lastimastes la cabeza". Irmanar-se, no caso dos Calel e de Nazareth, tem necessariamente a ver com uma relação com a linguagem e com a terra: com o entendimento de que há uma resistência política e cultural que passa por aquilo que comemos, pela maneira não capitalizada como podemos nos acolher uns aos outros, pelo modo com que nos comunicamos, pelas palavras e idiomas que articulamos. Aqui a condição periférica é potência à medida que não se coaduna nem com a ocidentalidade da América do Norte (fenômeno que Walter Mignolo aponta ao analisar os desdobramentos, no século XX, da expressão "hemisfério ocidental”), nem com o imaginário criollo, seja ele latino, seja ele anglo-saxão, e que ancoraria aquilo que W. E. B. Du Bois chama de dupla consciência. ${ }^{3}$ É assim que forças importantes emergem justamente às margens do Ocidente, mesmo que geograficamente se faça parte dele. Estamos fora desde dentro.

\footnotetext{
3 "A particularidade da imagem de hemisfério ocidental foi a de marcar, de maneira forte, a inserção dos criollos descendentes de europeus, em ambas as Américas, no mundo moderno/colonial. Esta inserção representou, ao mesmo tempo, a consolidação da dupla consciência criolla que se foi formando no próprio processo de colonização", diz Mignolo (2005, p. 38). As subjetividades criollas, assim, são forjadas na diferença colonial; a noção de "hemisfério ocidental", antes compartilhada pelos criollos (tanto anglosaxões como latinos) com relação à Europa, passa a ser uma consciência pós-colonial e nacional, dando espaço para a emergência de um colonialismo interno relativo aos povos ameríndios e afro-americanos.
} 
A transformação do hemisfério ocidental em Atlântico Norte assegura, por um lado, a sobrevivência do conceito de civilização ocidental. Por outro lado, marginaliza definitivamente a América Latina da civilização ocidental, e cria as condições para a emergência de forças que ficaram ocultas no imaginário criollo (latino e anglo-saxão) do hemisfério ocidental, isto é, a rearticulação de forças ameríndias e afro-americanas alimentadas pelas migrações crescentes e pelo tecnoglobalismo. (MIGNOLO, 2005, p. 48)

Tal rearticulação aparece, em Nazareth, a partir de um discurso sobre os meios e os fins: à primeira vista, reproduzindo o destino de tantos imigrantes do Sul em busca de uma vida melhor, o artista tem como télos, objetivo final, chegar aos Estados Unidos. Primeiro, lavando os pés na capital cultural e econômica do país, Nova York; depois, indo à feira de arte em Miami para a qual foi convidado. Tanto um momento quanto o outro é documentado com fotografias - principal material escolhido por Nazareth para registrar sua performance -, mas há muitos outros registros e escritos, como mencionado, feitos durante o percurso: no Brasil, no Chile, na Argentina, na Bolívia, na Nicarágua na Guatemala, no México ${ }^{4}$. Tão americanos quanto os Estados Unidos, esses países não adotam, como este último, o genitivo “da América” para designarem a si mesmos (muitas vezes, como se sabe, “América” é a única palavra usada pelos estado-unidenses a fim de nomear seu país). Esse lapso, apontado por autores como Eduardo Galeano, parece estar no campo de visão de Paulo Nazareth, que ruma para os Estados Unidos da América enquanto registra, à sua maneira, uma outra América, a Latina. ${ }^{5}$

\footnotetext{
${ }^{4} \mathrm{O}$ itinerário de Paulo Nazareth na performance Notícias da América é marcado menos por relações de causalidade e mais por contingências e desvios. Nas conversas que estabeleceu com a crítica e pesquisadora Janaína Melo entre março e novembro de 2011, nos damos conta desse modus operandi. Em maio de 2011, ele diz: "Estou aqui decidindo a rota... ainda estou em Bolívia, Cochabamba, não sei se vou a POTOSI... ou se sigo a La paz direto...a pouco estava decidido voltar para atrás e passar em Potosi... estou num zig zag... e não sou turista, definitivamente..." (NAZARETH, 2012, s/p) Na mesma fala, porém, Nazareth afirma que seu desejo de ir a Potosi se justifica porque havia ouvido falar num velho engenheiro de mina que teria muitas histórias sobre exploração do trabalho para contar. Mas, logo em seguida, diz que seu maior desejo é, na verdade, ir ao deserto: “A verdade é que queria passar pelo deserto... para buscar imagens que possam compor a coleção de nuvens que cruzam o deserto... já tenho nuvens do Saara vistas por cima...(...) queria o deserto do México e também os do Atacama (...) Além de ter descobertos histórias sobre mulheres que cavam o deserto em busca de corpos desaparecidos no período da ditadura militar..." (NAZARETH, 2012, s/p)

${ }^{5}$ No clássico ensaio "As veias abertas da América Latina", Galeano comenta: "Pelo caminho perdemos até o direito de nos chamarmos americanos, embora os haitianos e os cubanos já estivessem inscritos na História, como novos povos, um século antes que os peregrinos do Mayflower se estabelecessem nas costas de Plymouth. Agora, para o mundo, América é tão só os Estados Unidos, e nós quando muito
} 
América: Nazareth não apenas expõe a apropriação do termo feita pelos Estados Unidos, ele o redistribui do Sul ao Norte (invertendo assim a expressão “de Norte a Sul”). As notícias que produz com seus desenhos e registros fotográficos dão conta de um presente repleto de marcas dos projetos colonizadores e imperialistas, de violência policial, de desaparecidos, de disputas e articulações políticas, assim como de hábitos e culturas bem diversos, ou seja, de um presente que, ao ser duplicado nas imagens, tornase saturado de passados, para remetermos diretamente a Walter Benjamin e seu conceito de agoridade (Jetztzeit). ${ }^{6}$ Ao fazer isso, numa só tacada, Nazareth historiciza o momento presente e traz a performance para sua condição espaço-temporal mais básica: a do aqui e do agora. ${ }^{7}$

Estamos num tempo presente, em que o artista duplica o real ao produzir “notícias" como quem formula notas (escriturais e/ou imagéticas) de viagem, e parte desse material parece congregar forças oriundas de tempos anteriores - como as paisagens desérticas ou arruinadas (série sem título) em que Nazareth se deixa fotografar com a cabeça sempre coberta (e disso falaremos mais adiante) ou onde clica sofás em decomposição. Os retratos que faz de si ao lado de descendentes, mestiços ou não, dos povos originários, não podem ser tomados, ingenuamente, como puros documentos da realidade, tampouco como simples construções da realidade: eles são aquilo para o que Peter Burke (2017, p. 29) chama atenção em seu Testemunho ocular: o uso de imagens como evidência histórica: “(...) fotografias podem ser consideradas ambas as coisas: evidência da história e história".No caso dos (auto)retratos que Nazareth produz ao lado das pessoas que vai conhecendo ao longo da viagem, a evidência histórica apontaria para certa tendência na arte contemporânea, a do artista se comportar como etnógrafo, como bem apontou Hal Foster (2017) em seu conhecido texto. Criticando parte da arte contemporânea e sua recepção especializada quando estas amalgamam de maneira sistemática paradigmas de alteridade e identidade no imaginário acerca dos usos da ideia

habitamos uma sub-América, uma América de segunda classe, de nebulosa identidade." (GALEANO, 2010, p. 8)

${ }^{6}$ Sobre a agoridade, bem como a concepção benjaminiana de tempo e história, conferir, entre outros escritos, as Teses sobre o conceito de História (2010) e a seção N "Teoria do conhecimento, teoria do progresso", nas Passagens (2007).

7 Sobre ser o tempo presente a condição temporal da performance e o desejo de escapar à representação seu leitmotiv, ver Eleonora Fabião (2008) e Marvin Carlson (2010). 
de Outro, Foster alerta para o risco de o autor/artista assumir sucessiva ou simultaneamente os papéis de nativo, informante e etnógrafo sem problematizar as implicações políticas dessa prática.

Quando o artista está na identidade de uma comunidade localizada, pode ser solicitado a assumir o lugar dessa identidade, e representá-la institucionalmente. Nesse caso, o artista, por sua vez, é primitivizado, e mesmo antropologizado: eis aqui sua comunidade, é o que a instituição diz na realidade, encarnada em seu artista, agora em exposição. A maioria dos artistas relevantes tem consciência dessas dificuldades, e por vezes a enfatiza. (FOSTER, 2017, p. 182)

No caso de Nazareth, tal consciência crítica se manifesta à medida que fotografar a si mesmo ao lado de pessoas com aparência marcadamente não-ocidental faz com que o artista se implique naqueles recortes selecionados pelo seu olhar, e que implique também a nós, espectadores de sua obra: ao observarmos os retratos, nos deparamos com um artista em sua performance de longa duração ou com um sujeito que encena sua condição periférica/racializada/subalternizada ao lado de outros corpos periféricos a fim de flagrar o etnocentrismo e o eurocentrismo do nosso olhar, do nosso modo de ver a América Latina e consumir arte?

Nazareth também confronta o ideal moderno de progresso em seu ethos: primeiro porque, em vez de viajar de avião, prefere ir a pé e de ônibus, perdendo, portanto, mais tempo (e tempo, desde o início da modernidade, passou a ser o mesmo que dinheiro); segundo, porque em sua aparição na Art Basel, não apenas aparenta ser alguém que não deveria estar num espaço consagrado à exposição e comercialização de obras de arte, mas, uma vez lá dentro, expõe a si mesmo ao lado de artefatos que, no imaginário comum, têm pouco valor pois remetem ao atraso econômico e tecnológico da América Latina (as bananas e a velha kombi). Como se não bastasse, e de maneira tácita, esses mesmos artefatos relembram o gesto de Duchamp com a sua Fonte, colocando em questão o valor das outras obras de arte presentes na feira. Banana Market/Art Market: o mercado de arte e o mercado de bananas se encontram e equivalem um ao outro. Diferentemente de Duchamp, porém, não se trata, aqui, apenas, de um ready-made: o que 
está realmente em questão não é a possibilidade de inserir, no espaço institucional da feira de arte, objetos e/ou artefatos deslocados de seu contexto de produção e uso a fim de chamar atenção para o fato de que a operação autoral pode ocorrer somente no nível da linguagem, mas de produzir um discurso imagético contra-hegemônico e anticolonial dentro da instituição arte. Em vez de "recair na duplicidade da razão cínica na qual o artista e a instituição têm tudo ao mesmo tempo - conservam o status social da arte e exercem a pureza moral da crítica" (FOSTER, 2017, p. 180), Nazareth rasura esse status social ao sobrepor a mais-valia sobre corpos racializados e periféricos, ali representados por seu próprio corpo, com mercadorias de pouco valor.

Miami e Art Basel: à essa altura, Nazareth já produziu, também durante o trajeto, uma série sem título em que seu corpo é fotografado geralmente na horizontal e de perfil, com braços e pés estendidos, e só a cabeça oculta. Ele posa em paisagens arruinadas ou inóspitas ao extremo, com algum material muito volumoso lhe cobrindo inteiramente a cabeça: uma montanha de pedaços de tronco sobre a terra batida, um pequeno lago formado pelo encontro de recifes e o imenso mar ao fundo; pedaços do que deve ter sido uma construção sobre o meio fio, um arbusto sobre a areia de uma praia, flores brancas e miúdas à frente de um milharal. Madeira, água, entulho e vegetação cobrem a cabeça e o rosto do artista, cujo corpo, nessas fotos, parece o de um cadáver. No pathosformel ${ }^{8}$ em que se deixa fotografar, estaria ele se remetendo ao Cristo morto de Holbein ou ao acéfalo de Georges Bataille? Ou (e talvez ao mesmo tempo) faria uma alusão aos milhares (ou seria melhor dizer milhões?) de corpos desaparecidos nas Américas durante séculos de genocídios os mais diversos? São essas as perguntas da crítica de arte contemporânea Maria Angélica Melendi (2012, s/p). A resposta talvez esteja numa outra prática realizada na mesma viagem e que Melendi associa ao gesto

\footnotetext{
${ }^{8}$ Pathosformel é um conceito de Aby Warburg para designar aquilo que, nas imagens, é conservado através dos tempos. A expressão foi cunhada por Warburg em seu texto "Dürer e a Antiguidade italiana", de 1905, para demonstrar como o antigo gestual trágico greco-latino estava presente em um desenho do artista alemão, A morte de Orfeu. Warburg viu ali, assim como no trabalho de outros renascentistas nórdicos, a tentativa de incorporar, "na descrição da vida em movimento[,] as fórmulas genuinamente antigas para as expressões exacerbadas do corpo ou da alma" (WARBURG, 2015, p. 91). Assim, a pathosformel - fórmula patética -, em sua pós-vida ou em sua sobrevivência (Nachleben), permitiu que se desse conta da aparência dos corpos antigos às voltas com suas próprias modificações no século XV: se o pathos pode designar um movimento e/ou um afeto transitório, a fórmula o inscreve em sua duração - o que muda permanece.
} 
insubmisso de Cildo Meireles quando este, nos anos 1960, denunciava a ditadura militar no Brasil de maneira bastante eficaz:

\begin{abstract}
Usando um recurso popular apropriado por Cildo Meireles, e depois dele, infinitamente utilizado por outros artistas do continente, Paulo carimba as cédulas de dinheiro que utiliza na sua viagem: [PARA DEMOSTRAR GENOCIDIOS PASADOS EN LAS AMERICAS antes del pago APUNTE EL NOMBRE DEL(A) DESAPARECIDO(A), PAIS DE ORIGEM, y/o ETNIA y periodo histórico (colonia, imperio, dictadura, democracia)]. (MELENDI, 2012, s/p).
\end{abstract}

Indo do Sul rumo ao Norte, partindo do mundo colonizado em direção ao mundo colonizador, além de realizar registros fotográficos, Paulo Nazareth dissemina denúncias em cédulas, transporta objetos como "um arame enrolado, uma gaiola velha, um computador que vive caindo" a fim de trocá-los por outras coisas que possam lhe interessar (NUNES, 2012, s/p), bem como coleta hábitos e modos de vida, levando tudo isso até os Estados Unidos. É um nômade, um coletor de "experiências, naturais, culturais, violentas, poéticas, encontradas nas paisagens, ugares, e poeira. Muita poeira", afirma a curadora e crítica de arte Janaina Melo (2012, s/p). Se tais experiências se acumulam no corpo do artista que as coleta, a decisão de não lavar os pés tem, nesse sentido, um valor que ultrapassa o simbólico. A poeira passar a ser um indício material, um resíduo daquilo com que o corpo de Paulo Nazareth entrou em contato - a poeira passa a ser, portanto, um instrumento da performance de longa duração, performance essa que flerta com sua própria dimensão ritual durante a lavagem dos pés do artista no rio Hudson. Estamos diante de um dispositivo que a crítica Diana Taylor (2013) define como repertório: aquilo que o corpo, nas práticas performáticas em seus mais diferentes aspectos, é capaz de manejar/acumular/transmitir. O repertório encontra na performance um ativador de saberes, de culturas materiais, e prescinde, muitas vezes, de uma prática arquivística sistemática, escritural e ocidental. (Idem) Nesse sentido, o nomadismo em Nazareth Ihe permite coletar experiências e matérias diversas, bem como flertar com uma dimensão cósmica das relações espaço-tempo no ato ritual realizado no rio Hudson. Como se a experiência performática de se autodeslocar pudesse afetar não só a si 
mesmo, mas também as coisas encontradas pelo caminho, transformando o Norte em Sul - como se pudesse fazer o relógio girar no sentido oposto ao do progresso. Como se pudesse, portanto, escova a história (e as geografias) a contrapelo.

Escovar a história a contrapelo. A famosa expressão de Walter Benjamin, formulada nas Teses sobre o conceito de história, ensaio escrito nos primeiros anos da Segunda Guerra Mundial, aponta para uma crítica contumaz à ideia de progresso. Este seria, ainda em Benjamin, uma “tempestade” que, “de maneira irresistível”, impele o Angelus Novus, pintura de Paul Klee, "para o futuro" (BENJAMIN, 2010, p. 226). O anjo da história, nos diz Benjamin, gostaria de deter-se sobre as catástrofes a fim de "acordar os mortos e juntar os fragmentos", mas a tempestade imobiliza suas asas (BENJAMIN, 2010, p. 226).

Em todo o mundo, a última tempestade de progresso trouxe consigo, desde os anos 1980, o neoliberalismo, a globalização, o desencanto com as utopias e a sensação de que o presente não para de se alongar. É o que o historiador François Hartog (2013, p. 15) define como presentismo: "De um lado, um tempo dos fluxos, da aceleração e uma mobilidade valorizada e valorizante; do outro, (...) a permanência do transitório, um presente em plena desaceleração, sem passado - senão de um modo complicado (...), e sem futuro real tampouco (...)."

Na América Latina, ao presentismo de Hartog é preciso acrescentar os traumas do passado colonial; levar em conta os ciclos econômicos, as ditaduras militares e seus crimes. Aqui e agora, a modernidade subsiste não como "espírito do tempo", mas como uma série de consensos rotos que operam dentro de um imaginário coletivo comum reciclado pela ideologia neoliberal. Noções como progresso e crescimento, por exemplo, continuam a ser caras a diferentes setores das sociedades de consumo - setores que não conseguem ou não querem rever premissas que promoveram sucessivas catástrofes, como os processos colonizatórios e suas atualizações na dialética entre o local e o global, para ficarmos com um dos aspectos que o trabalho de Nazareth ecoa. Sobre esse tema, Andreas Huyssen dá uma importante contribuição com o ensaio Culturas do passadopresente: modernismos, artes visuais, políticas da memória ao afirmar a necessidade de se pensar a modernidade e o modernismo fora do eixo Atlântico Norte não como simples decalques, consequências ou imitações dos fenômenos artísticos e culturais ocorridos 
nos países europeus, mas como processos multifacetados cujas características complexificam tanto o passado colonial quanto o presente global.

Então como agora, a modernidade nunca foi uma só. A nova narrativa das modernidades alternativas, nos estudos e na antropologia póscoloniais, nos faz revistar variedades do modernismo antes excluídas do cânone euro-americano como derivadas e imitativas e, portanto, inautênticas. A mudança de perspectiva é ainda mais apropriada na medida em que pudemos compreender o colonialismo e a dominação como a própria condição de possibilidade da modernidade e do modernismo estético. (...) Claramente, o novo interesse pelos espaços da modernidade no século XX, fora do Atlântico Norte, deve fazer parte do debate sobre a globalização, sobretudo se estivermos interessados na genealogia do global, que não nasceu da cabeça do capitalismo pósGuerra Fria". (HUYSSEN, 2014, p. 21)

Huyssen dá alguns passos atrás na linha do tempo de Hartog e defende que as dimensões culturais da globalização e seus elos com a história da modernidade continuam mal compreendidas. Se reconhecermos que não existe história da modernidade sem história da colonização, seríamos obrigados a repensar as forças que propiciaram a ascensão da ideologia neoliberal e o advento da globalização. Assim, o lugar-comum de que a cultura "real” ou "autêntica" é "aquela que é subjetivamente compartilhada por uma dada comunidade e, portanto, como cultura local, ao passo que apenas os processos econômicos e a mudança tecnológica são percebidos como universais e globais" é algo que também precisaria ser revisto. (HUYSSEN, 2014, p. 23) Nessa visão dicotômica, diz Huyssen (2014, p. 23), "o local se opõe ao global como tradição cultural autêntica, enquanto o global funciona como 'progresso', isto é, como uma força de alienação, dominação e dissolução".

Na performance de Paulo Nazareth, tal oposição é constantemente encenada e cancelada, uma vez que ele pratica uma espécie de "cosmopolitismo do pobre", para usar a expressão do crítico Silviano Santiago: percorrendo a América Latina em busca de um comum que nunca se completa, adquirindo repertório (no sentido proposto por Diana Taylor), refazendo cartografias, recolhendo resíduos coloniais, ditatoriais; e sobrepondo, a partir do próprio corpo, temporalidades modernas e contemporâneas, Nazareth faz de 
cada localidade a que ainda não chegou um "futuro" a contaminar com "passados". O artista reembaralha, assim, regimes temporais e culturais. E se, por um lado, como problematizam Mignolo e Quijano, a América Latina nunca é ocidental o suficiente, sendo vista como um reservatório primitivo, portanto arcaico, da cultura, por outro, como afirma a crítica argentina Josefina Ludmer em Aqui América Latina, há uma ideia de futuro que se colou ao imaginário da região e que aponta para sua "incompletude" frente a um estado civilizatório ideal. Acredito que Nazareth consegue flagrar essa contradição. Citemos Ludmer (2013, p. 22):

Imaginemos que as modernizações latino-americanas (as mudanças na história do capital e as mudanças das políticas imperiais pela internacionalização da economia) se produzem por saltos ou por cortes temporais, de modo que nos legam um desenvolvimento (...) "natural", para dizê-lo de certo modo, "uma história" que trilharam os grandes centros para chegar a esse ponto global. De repente interrompem alguma coisa que poderia continuar sendo e, num movimento de transformação radical e forçosa (...), por decreto, nós, latino-americanos, permanecemos instalados em outra situação e em outra história. O corte de tempo como regime histórico faz com que a América Latina nunca esteja completa, que seu ser seja sempre remetido ao futuro, sendo essa uma das ideias-chave de nossa posição global.

Nosso "ritmo" em relação ao Norte "desenvolvido" nos colocaria sempre numa “etapa temporal anterior atrasada" (LUDMER, 2013, p. 22). Essa miopia crônica, nos anos 2000, teria ensejado o que Ludmer chama de "tempo zero": "resultado da aniquilação temporal", ele "é a simultaneidade global, chave para os mercados financeiros, que mudou a experiência da vida e da natureza do trabalho, convertendo-o em trabalho imaterial" (LUDMER, 2013, p. 14).

“Tempo zero”, versão latino-americana de presentismo, é o efeito temporal de nosso mais recente salto modernizador. Porém, a cada salto gera-se "um tempo não vivido", com suas lacunas, seus vazios temporais que teimam em se repetir e voltar (LUDMER, 2013, p. 23). A partir dessa brecha, Ludmer defende que devemos buscar relatos e imagens sem o "imperativo de modernização emancipatória” (LUDMER, 2013, p. 23) - trabalhos que fabriquem um presente; que formem uma "urdidura de palavras e 
imagens de diferentes velocidades, graus e densidades, interiores-exteriores a um sujeito, o que inclui o acontecimento, mas também o virtual, ${ }^{9}$ o potencial, o mágico e o fantasmático". (LUDMER, 2013, p. 127-129) A teórica argentina se refere, é certo, a trabalhos literários, mas aqui gostaríamos de forçar os limites entre os fazeres artísticos, partindo da própria noção de pós-autonomia por ela cunhada, ${ }^{10}$ e incluir, nessa visada, a performance de Paulo Nazareth, que responde ao apelo para se "fabricar um presente" (LUDMER, 2010, p.1) desde que se entenda esse fabrico, entre outras coisas, como uma forma de manejar temporalidades não aparentes. Afinal, falar de velocidades, bem como de virtual, potencial e fantasmático é dar conta de regimes temporais ainda não atualizados, ou seja, que não se encontram no presente, mas no futuro ou no passado. ${ }^{11}$

\footnotetext{
${ }^{9}$ A noção de "virtual" à qual se refere Ludmer se apoia em Gilles Deleuze, que por sua vez parte das considerações de Henri Bergson em "Matéria e memória". Para Bergson, o passado, ao se constituir como uma dimensão virtual do presente, pode ser atualizado a qualquer momento, guardando em si mesmo uma potência de futuro (BERGSON, 1999, p. 158, 163, 180). A partir de Bergson, Deleuze dirá que todo objeto ou situação tem um duplo aspecto, sem que suas duas metades se assemelhem, sendo uma virtual e, a outra, atual (DELEUZE, 2004, p. 295 e 296). A dimensão virtual guardaria o futuro, mas também o passado, e ela é o que torna possível que se tenha consciência do tempo que passa e que eventos imprevistos e ações livres possam de fato ocorrer, ou seja, atualizar-se, tornar-se presentes. A proposta de um virtual em Deleuze aparece como algo dinâmico, não como uma oposição à realidade ou como um simples possível (o futuro não cabe no campo das probabilidades). Não se trata de dar espaço a uma possibilidade que irá se realizar, pois a realização do possível implica necessariamente uma semelhança e uma limitação com o que já se pode imaginar ou com o que já aconteceu. (Ibidem, pp. 299 e 300). Mesmo tendo sido passado, o futuro, quando se configura nos termos de um virtual, nos chega em diferença.

${ }^{10}$ Basicamente, Ludmer se refere a escritas que funcionam como inscrições, que não admitem leituras literárias, que não reivindicam um campo autônomo de atuação ou uma separação clara entre realidade e ficção (LUDMER, 2010, p.1).

${ }^{11}$ Em Tempo passado: cultura da memória e guinada subjetiva, outra argentina, Beatriz Sarlo, também se dedica a pensar as produções artísticas no tempo presente, mas o faz abordando de maneira direta quais são os usos possíveis da permanência do passado no agora. Mesmo quando o passado é forçosa e sistematicamente esquecido pelo Estado ou pela família a fim de encobrir um crime ou uma violência, "só de modo aproximativo ou figurado ele é eliminado, a não ser que se eliminem todos os sujeitos que o carregam (seria esse o final enlouquecido que nem a matança dos judeus conseguiu ter). Em condições políticas e subjetivas 'normais', o passado sempre chega ao presente" (SARLO, 2007, p. 10). Assim como em Ludmer, a matriz do pensamento de Sarlo, aqui, é deleuziana. Ela afirma: "Poderíamos dizer que o passado se faz presente. E a lembrança precisa do presente porque, como assinalou Deleuze a respeito de Bergson, o tempo próprio da lembrança é o presente: isto é, o único tempo apropriado para lembrar e, também, o tempo do qual a lembrança se apodera, tornando-o próprio." (Idem)
} 


\section{Uma performance pós-utópica}

Num ensaio-balanço sobre o legado das vanguardas poéticas dos anos 1960, Haroldo de Campos cunharia um termo que gostaríamos de usar, neste artigo, como operador conceitual: o pós-utópico. Ao discorrer sobre a aliança incontornável entre vanguarda e utopia, constatando a morte das mesmas, no contexto brasileiro, com o golpe de 1964 e o fechamento político que a esse fato histórico se sucedeu, Campos (1997, p. 268) afirma que a poesia "viável do presente" é uma poesia de "pós-vanguarda, não porque seja pós-moderna ou antimoderna, mas porque é pós-utópica". A poesia atual seria uma "poesia do outro presente", e da "história plural" que implica uma “crítica ao futuro" e seus “paraísos sistemáticos”. (...)

Esta poesia da presentidade, no meu modo de ver não deve, todavia, ensejar uma poética da abdicação, não deve servir de álibi ao ecletismo regressivo ou à facilidade. Ao invés, a admissão de uma "história plural" nos incita à apropriação crítica de uma pluralidade de passados, sem uma prévia determinação exclusivista do futuro. (CAMPOS, 1997, p. 268-269)

Estendendo essa política estético-temporal a outras poéticas (do texto em prosa e das artes visuais) e considerando-a mais como programa do que como diagnóstico, passados mais de trinta anos desde a redação de "Poesia e modernidade: da morte da arte à constelação, o poema pós-utópico", vemos que Campos, de certa forma, esvaziou o debate modernidade X pós-modernidade já naquela época e apontou para aquilo que, hoje, críticos de arte como Maria Angélica Melendi enxergam como um tipo de resistência política e cultural no contemporâneo: a tarefa da arte seria, agora, de "criar espaços livres, propor temporalidades cujo ritmo atravess[e] aqueles que organizam a vida cotidiana" (MELENDI, 2017, p. 65); antes de formular e tentar impor "qualquer programa revolucionário", a arte, hoje, "parece ter o poder de recodificar signos culturais" (MELENDI, 2017, p. 57).

Tratar-se-ia, no caso de Nazareth, de entrar e sair dos tecidos sociais, das comunidades locais, em vez de representá-las ou de se inspirar nelas. Separadas (ou unidas?) por fronteiras a delimitar os estados-nações, em Nazareth elas sugerem outros 
intercâmbios políticos, culturais e artísticos para o presente que não aqueles vigentes nos sistemas integrados ao capitalismo global, como demanda Ludmer com relação à literatura pós-autônoma. Operando com uma espécie de "resíduo utópico" (CAMPOS, 1997, p.269), tal performance lançaria mão das dimensões crítica e relacional típicas dos anos 1960, mas com viés teleológico já bastante enfraquecido. Como outros trabalhos da contemporaneidade, Notícias da América seria "como um interstício social, um espaço de relações humanas que, ao se integrar mais ou menos harmoniosa e abertamente no sistema global, sugeriria outras possibilidades de intercâmbios que aqueles vigentes nesse sistema" (MELENDI, 2017, p.64).

Interessa levar em conta as reflexões de Campos e Melendi sobre a poesia e a arte contemporâneas à medida que elas dão conta de um fenômeno que ocorre em diferentes campos artísticos e que parece ir ao encontro da proposta de Paulo Nazareth em Notícias da América. Ao criticar, ainda que indiretamente, uma ideia promissora de futuro, confrontando-a com imagens feitas na segunda década do século XXI, mas que parecem trazer algo do passado - imagens que remetem à colonização, de um lado, e à herança ancestral, de outro -, Paulo Nazareth lida com o presente respondendo a ele por um viés pós-utópico e a partir de uma concepção heterocrônica do tempo: o futuro foi atualizado naqueles que sobreviveram à colonização e que resistem ao capitalismo neoliberal das últimas décadas, não sem antes terem passado por um processo de modernização muitas vezes forçada durante o século XX e por sangrentas ditaduras militares. Falamos de um presente saturado de agoras, como formula Walter Benjamin em suas teses sobre o conceito de história: não estamos tomando o passado colonial mais longínquo como um tempo que simplesmente antecede os projetos modernizadores do início do século passado e que se encontra distante dos regimes autoritários de direita que assolaram o continente nos anos 1960, 1970 e 1980. Abandonando-se uma perspectiva linear do tempo, o presente deixa de ser um continuum do passado e passa a conter muitos passados, cuja virtualidade depende de dispositivos de enunciação capazes de atualizálos em palimpsesto.

Além disso, é no tempo presente que se dão as trocas e os intercâmbios entre o artista e as pessoas encontradas ao longo da jornada, uma vez que o corpo performático 
afeta e é afetado: Paulo Nazareth não é "apenas" um viajante-performer que vai “denunciar" o passado dos vencidos, para usar, outra vez, um termo benjaminiano. Há uma poética da performance em curso: ela é cheia de pequenas durações dentro do grande arco espaço-temporal Minas Gerais-Nova York, ela acontece fora dos olhos do público (o que vemos dela são os relatos, as notícias que o artista produz em forma de imagens e de alguns textos), ela ganha força quanto mais essa diáspora voluntária empurrar o artista para fora do que é supostamente seu - sua casa, seu bairro, sua cidade, seu país, sua língua.

havia estabelecido 5 cosas a preservar antes de salir de casa: mi vida, mi passaporte, mi tajeta o billetera, mi disco duro o HD externo, e la quinta ya no me acuerdo... perdi el disco duro hace mucho y ahora acaban de llevar mi passaporte... bueno tengo mi vida, la billetera y la quinta cosa mientras no me acuerdo creo que sigue comigo... seria mi optimismo? Jejeje... estoy bien, bueno quiza la casualidade me desea mas tempo desde lado... (NAZARETH, 2012, s/p)

Sem HD, sem passaporte, mas ainda com a carteira, a vida e com uma quinta coisa da qual ele simplesmente não se lembra. Em que medida, nesse jogo de ganhar-e-perder, Nazareth abre mão de uma identidade inequívoca? Não se trata de querer estetizar tudo o que está fora da cena, mas de ver como é possível realizar o gesto político que interessa: promover uma abertura, em si mesmo e no mundo, e é isso o que ele faz. Afinal, como um homem mestiço e maltrapilho do Sul poderia ser reconhecido como um artista no Norte? (A irônica e decisiva frase de Magritte, Ceci n'est pas une pipe, ecoa aqui de maneira perversa: Isso não é um artista). Estaria ele dentro ou fora do sistema da arte? Uma possível resposta pode se insinuar num momento de sua performance. Ao chegar à fronteira entre os Estados Unidos e o México, seu plano é quase cruzá-la para então dar meia-volta e pernoitar mais uma vez em solo mexicano. Faz esse movimento de ir, quase chegar e voltar durante dias seguidos, muito antes do muro de Trump... Durante esse período, Nazareth produz fotos em que segura cartazes de papelão com dizeres evidenciando as condições de invisibilidade e/ou criminalização sofridas por corpos como 
O seu. Frases como "I clean your bathroom for a fair price" e "Vendo mi imagen de hombre exótico" dão o tom.

Ele sobrepõe circuitos artísticos, temporalidades (o passado colonial, o presente neoliberal), territórios (os países latino-americanos e, por fim, os Estados Unidos da América), povos e etnias, realizando aproximações geopolíticas - o homem mestiço e pobre sai a pé de Governador Valadares e conhece indígenas mexicanos, brasileiros, peruanos, bolivianos, equatorianos, guatemaltecos... registra a si mesmo e a eles no projeto Cara de índio, que consiste de fotografias ou panfletos em papel-jornal onde se lê:

Projecto: CARA DE ÍNDIO ---- identificar índios urbanos, desde o extremo sul ao extremo norte das Américas. Por me ao lado de índio urbano e comparar a cara mestiça à cara do outro... (NAZARETH, 2012, s/p)

Iniciado em 2011, ainda em Governador Valares, o projeto promove uma série de aproximações e afastamentos, semelhanças e diferenças entre indivíduos não-brancos cuja identidade étnica pode variar. Paulo ora fica mais índio, ora mais negro, dependendo daquele com quem posa. Uma vez nos Estados Unidos, adquire a forma de um camaleão:

Com essa história de ser mestiço e viajar por América, mudo de cor todos os dias... em casa as gavetas não estão tão bem definidas, mas seguindo ao norte tudo é bem arrumado, há o bairro dos negros, dos árabes, dos chicanos e outros tantos. Tem dia que sou niger/preto/negro, mas não posso abrir a boca porque assim posso mudar de cor, tem dia que sou árabe, paquistanês, índio e outros tantos adjetivos que podem mudar de acordo com os olhos do outro e as palavras de minha boca. Seja como for, às vezes nos Estados Unidos da América, quando eu entro em lojas de "brancos", todos ficam com medo, incluindo eu. (NAZARETH, 2012, $\mathrm{s} / \mathrm{p})$

Nessa performance-jornada, o corpo de Paulo Nazareth e de tantas outras pessoas como ele são materialidades muito distintas e "impróprias" que se juntam a outros materiais - carrocinhas de diablitos e chamoyadas, entulhos, cartazes de papelão, plantações de repolho. Tudo isso, quando registrado nas fotografias que atestam o gesto 
performático, forma não uma comunidade imaginada como aquela formulada por Benedict Andersen num espírito crítico à ideia de nacionalismo, mas uma comunidade performaticamente criada. Nela, o artista não é o etnógrafo que documenta tipos, mas que flagra o olhar etnocêntrico do público ao produzir sucessivos deslocamentos.

\section{Dentro ou fora? Aqui}

Uma performance capaz de atualizar temporalidades (de promover temporalidades impuras ${ }^{12}$ ) que complexificam nosso regime de historicidade no presente; um trabalho de hibridização que precisa de uma condição geopolítica, portanto espacial, para acontecer. Essas características podem encontrar eco no debate sobre a nãoespecificidade do médium, sobre o fim da autonomia da obra de arte e sobre as transformações sofridas pelas instituições que tradicionalmente a acolhem, sendo este último ponto um dos focos de Paulo Nazareth desde a série de panfletos "Aqui é arte", da qual falaremos mais adiante.

Ler Paulo Nazareth a partir da ideia de temporalidades impuras implica problematizar outra ideia, a de contemporâneo, já que é esse modo espaço-temporal, e não a "pós-modernidade", o que hoje parece ser o pano de fundo a situar não só a produção do artista mineiro, mas de muitos outros ao redor do mundo. Em Brouhaha, les mondes du contemporain (2016), o crítico e pesquisador francês Lionel Ruffel mapeia, em diferentes centros e atores de produção artística, política e/ou acadêmica do mundo globalizado, o uso do termo contemporâneo, assim como as disputas suscitadas por esse uso. Entendendo o conceito como um paradigma tradutor daquilo que é horizontal, múltiplo e descentrado, Ruffel, em vez de partir ou de se referir ao notório ensaio de Giorgio Agamben como fundamento de sua pesquisa, toma-o como uma entre muitas intuições em torno de nossa condição espaço-temporal. A partir de 2004, na cidade argentina de Rosario, em Nova York, em Santiago do Chile, em Rouen, em Hong Kong, em

\footnotetext{
${ }^{12}$ A expressão é cunhada por Georges Didi-Huberman em Diante do tempo (2015) na tentativa de explorar os diferentes e complexos tempos da imagem artística e propor um outro tipo de abordagem epistemológica para a história da arte.
} 
Veneza (com Agamben), começam a pipocar experimentos teórico-práticos em torno do termo. A pergunta “O que é o contemporâneo?”, aliás, teria sido feita pela primeira vez em Rosario, no Centro de Expresiones Contemporáneas (CEC), um ano antes do lançamento do ensaio de Agamben.

Criado nos anos 1990 e destinado a funcionar como um pólo de convergência, de cruzamento, em que signos, gestos, linguagem e mecanismos - isto é, expressões afastavam programaticamente a palavra arte, o CEC perguntou pela primeira vez o que era o contemporâneo que constituía seu nome até então como adjetivo justamente quando em Rosario se inaugurava um Museu de Arte Contemporânea. A pergunta, feita numa série de ensaios da revista Zum, diz Ruffel, era o resultado da inquietação ao se verificar que um centro de expressões e um museu de arte compartilhavam, no entanto, o mesmo termo: contemporâneo.

Na pergunta da revista Zum, o que se queria saber era que noção de partilha, de comum - a saber, de espaço comum - estava em jogo, uma vez que instituições essencialmente modernas como museu e arte passavam a disputar o termo contemporâneo. Para Ruffel, "a primeira reflexão teórica sobre o conceito de contemporâneo" é uma "reação à institucionalização da Arte (com maiúscula) contemporânea" (RUFFEL, 2016, p. 41). A ideia de centro como pólo aglutinador, aqui, é fulcral, à medida que Ruffel mostra, com outros exemplos (sendo o principal deles o Centre Georges Pompidou, em Paris), que todo um pensamento artístico e arquitetural pós-68 se dispôs a pensar os espaços públicos de partilha do sensível, para usar o termo de outro francês, o filósofo Jacques Rancière, de maneira menos restrita, mais abrangente e periférica: em vez de um museu, de "um lugar sacralizado, dedicado à contemplação (...) um novo espaço multifuncional, voltado para a experiência, o centro de arte". (Ibidem, p. 36) Sua principal característica seria a de abrigar, num mesmo espaço, biblioteca, cinema, instituto de pesquisa, espaço para apresentações ao vivo e... obras de arte. Estas são concebidas, portanto, como elementos fundamentais na promoção de uma esfera pública e comum de criação, mas não como os únicos. A arte é um também que agora se encontra em espaços mais abertos, menos encerrados em si mesmos - menos autônomos. 
Essa expansão do espaço público - e, por consequência, essa expansão do espaço da arte - engendra mudanças formais no próprio fazer artístico, algo que começa nos anos 1960 e que Rosalind Krauss mapeia em "A escultura no campo ampliado" (2008) e em A Voyage on the North Sea - Art in the age ofthe post-medium condition (1999). Neste último, Krauss problematiza a ideia de inespecífico nas artes ao mostrar como, a partir dos trabalhos com viés literário e ficcional do poeta e artista conceitual Marcel Broodthaers (Ma collection e Musée d'Art Moderne, Departement des Aigles), não faria sentido falar num simples oposto para o conceito de específico a fim de descolar-se de uma concepção modernista.

Krauss propõe pensar a especificidade dos mediums, mesmo os modernistas, como "diferencial, autodiferenciada, e assim como uma estratificação de convenções nunca simplesmente colapsadas à materialidade de seus suportes. (...) Nas mãos de Broodthaers, a ficção se tornou ela mesma esse médium, essa forma de especificidade diferencial" (KRAUSS, 1999, p. 53).

Pouco mais de vinte anos depois da publicação do ensaio "A escultura no campo ampliado", em que defendia com menos nuances o conceito de inespecificidade, Krauss retoma a discussão argumentando que experimentos como os de Broodthaers apontavam para o que a arte contemporânea passaria a defender: a implosão da especificidade do médium poderia prescindir da especialização da arte, mas não de uma certa espacialização e de problematizar seu estar no tempo. Dito de outro modo: para resguardar a arte do mercado e das instituições, não bastaria torná-la conceitual; seria preciso também enunciar um espaço-tempo para ela, espaço-tempo esse que poderia se autodiferenciar junto com a obra à medida que elementos lhe fossem retirados ou introduzidos - dar e/ou tirar espessura.

Nazareth parece saber bem disso em um de seus primeiros trabalhos, a série Aqui é arte (2007), onde se pode notar uma mudança estratégica com relação à discussão que balizou a arte moderna desde o gesto de Duchamp: graças ao uso do advérbio de lugar "aqui", dispensando-se assim o uso de um pronome demonstrativo como "isso", por exemplo, já não se trataria mais de saber o que é ou não é arte, mas onde a arte está, isto é, que agências farão arte e território (o que já fora dito em potência com o ready-made). A 
série consiste na produção de folhetos fotocopiados em papel de péssima qualidade que, num ato de fala, ${ }^{13}$ marcam o território da arte.

Aqui é arte promove a espacialização do performativo. Sua escrita inscreve ao mesmo tempo que institui. Trata-se de uma intervenção, de uma declaração e, também, da forma embrionária de um manifesto, este último sendo a conhecida borda entre a vida e a arte, entre a vida e a escrita, entre a escrita e o programa, entre o programa e as ações. Contra o que Nazareth se insurge? O que propõe? É curioso ver o desconserto com que suas experiências são tratadas na mídia ${ }^{14}$ - espanto e cinismo acabam por defini-lo pela lógica da meritocracia: ele é retratado como um rapaz pobre que chegou ao alto circuito da arte. Seu corpo intruso é um estranho e insignificante desvio a contornar/absorver na máquina neoliberal global.

O avanço dessa máquina pode ser sentido em muitos lugares do mundo e de diferentes maneiras. Dizer "aqui é arte" onde menos se espera - como por exemplo no escoadouro da Lagoa da Pampulha, num muro com um buraco na Avenida Doutor Otacilio Negrão de Lima, em Belo Horizonte - e transitar por territórios de forma não predatória é um gesto pequeno, mas é também mais uma entre muitas iniciativas descentradas de redirecionar os afetos, como foram as ocupações surgidas em diferentes partes e épocas nos últimos dez anos (para ficarmos com apenas um exemplo recente, no Brasil: o das escolas pelos secundaristas brasileiros nos anos de 2015 e 2016).

Delineia-se, assim, a partir de uma visada flexível sobre a forma, ou melhor, sobre uma arte menos formalista e menos autônoma, a de Paulo Nazareth, com um

\footnotetext{
13 A expressão foi cunhada pelo linguista e filósofo inglês J. L. Austin com sua teoria dos atos de fala. Basicamente, Austin (1962) se perguntou como um discurso pode realizar, no mundo social, a ação à qual se refere. Ele propôs que se diferenciasse duas espécies de elocuções: as constativas e as performativas. Quando se diz “Hoje faz sol”, por exemplo, descreve-se um determinado estado de coisas, o qual é passível de ser verdadeiro ou falso: se estiver chovendo, alguém poderá objetar e dizer que é falsa a afirmação de que está fazendo sol. Por sua vez, as elocuções performativas não seriam nem verdadeiras, nem falsas; não descreveriam nada, mas ensejariam um ato. Se um juiz diz "Eu os declaro marido e mulher", sua palavra tem o poder de instituir uma nova realidade legal sobre os corpos daqueles que se casam. Essa primeira distinção de Austin capta uma diferença importante, tornando visível o fato de a linguagem realizar ações em vez de simplesmente comunicá-las, mas o linguista percebe que as elocuções constativas também são capazes de fazer algo que não só representar: dependendo das circunstâncias, haveria nelas uma performatividade implícita. Mesmo se for lida como uma constativa, a frase "Aqui é arte" guarda em si uma promessa, uma adesão, e já aí um fazer.

${ }^{14}$ Conferir as matérias de Audrey Furlaneto, "Um artista exótico" (2013) e de Mariana Zylberkan, "Paulo Nazareth, o andarilho das artes" (2012), publicadas respectivamente no jornal O Globo e na Veja.com.
} 
pensamento próprio e sutil sobre o tempo e os meios. Estes são mais do que um suporte físico, podendo ser definidos pela superposição de materialidades, épocas e discursos. Sua expansividade termina por extrapolar partições como realidade/ficção, artístico/nãoartístico, literário/não-literário, uma vez que seus escritos são muitos: para além da série Aqui é arte há outros panfletos, alguns produzidos durante a realização de Notícias da América, como os do projeto Cara de índio, mas também aqueles em que a performance aparece como protocolo, à la grupo Fluxus ("Como matar um porco para um casamento" e a série Artexperience, ambos de 2009) ou onde a própria escrita tende a ser a performance (Important Public Notice, de 2006, e QUÉ FICÁ BUNITO, de 2010). Tais escritos, muitos redigidos em espanhol e/ou contendo construções inusitadas, erros gramaticais e ortográficos desconcertantes, não admitem uma leitura literária nem verossímil, nem tampouco são apenas registros, diários ou impressões. Onde estão? Que efeitos desejam produzir? Não importa se são realidade ou ficção, se estão dentro ou fora do sistema da arte - ou, melhor dizendo, se entram e saem desse sistema a todo momento. Produzidos localmente, seja em ilhas urbanas, seja no deserto mexicano ou no extremo sul das Américas, não podem ser lidos apenas a partir de categorias artísticas, como artista, obra, estilo, escola, sentido: como uma massa de signos acompanhando as performances e lhes servindo de fomento, eles promovem uma drástica operação de esvaziamento e inscrição, abrindo palavra e corpo para uma configuração espaçotemporal complexa, fabuladora, como num pequeno texto em que o artista define a si mesmo e do qual reproduzimos um trecho:

Um día llegó um hombre lejano a esperar que uma ballena viniera a morir a su lado, se murió en del desierto y sus huesos se hicieron polvo y se mezclaron a las arena a que se miran desde el mar donde llegan las ballenas a tener sus crias [ensayo de uma pequena leyenda dedicada a la península de la Baja California si por casualidade me muero em uno de los muchos desiertos que ahí están] (NAZARETH, 2012, s/p)

\section{Bibliografia}

AUSTIN, J. L. How to do things with words. London: Oxford University Press, 1962. 
BENJAMIN, Walter. Teses sobre o conceito de história. In: Magia e técnica, arte e política. Obras escolhidas I. Trad. Sergio Paulo Rouanet. São Paulo: Brasiliense, 2010 ( $1^{\text {a }}$ edição 1994).

. Passagens. Org. Willi Bolle. Trad. Irene Aron, Cleonice Paes Barreto Mourão. Belo Horizonte/São Paulo: Editora UFMG/Imprensa Oficial do Estado de São Paulo, 2007.

BERGSON, Henri. Matéria e memória. Trad. Paulo Neves. São Paulo: Martins Fontes, 1999.

BOLAÑO, Roberto. 2666. Trad. Eduardo Brandão. São Paulo: Cia das Letras, 2010.

BURKE, Peter. Testemunho ocular: o uso de imagens como evidência histórica. Trad. Vera Maria Xavier dos Santos. São Paulo: Edusc, 2017.

CALEL, Edgar. "Avulsos de viagem". In: Arte contemporânea LTDA. Rio de Janeiro: Cobogó, 2012.

CARLSON, Marvin. Performance, uma introdução crítica. Trad. Thaïs Diniz, Maria Antonieta Pereira. Belo Horizonte: Editora UFMG, 2010.

CAMPOS, Haroldo de. "Poesia e modernidade: da morte da arte à constelação, o poema pós-utópico”. In: O arco-íris branco. São Paulo: Imago, 1997.

DELEUZE, Gilles. Diálogos (com Claire Parnet). Trad. José Gabriel Cunha. Lisboa: Relógio D’Água, 2004.

DIDI-HUBERMAN, Georges. Diante do tempo. Trad. Vera Casa Nova e Márcia Arbex. Belo Horizonte: Editora UFMG, 2015.

. Sobrevivência dos vagalumes. Trad. Vera casa Nova e Márcia Arbex. Belo Horizonte: Editora UFMG, 2011.

FABIÃO, Eleonora. "Performance e teatro - poéticas e políticas da cena contemporânea.” Revista Sala Preta, PPGAC, Escola de Comunicação e Artes da Universidade de São Paulo, vol. 8, 2008, pp. 235-246.

FOGWILL, Rodolfo. Runa. Buenos Aires: Interzona, 2003.

FOSTER, Hal. O retorno do real. Trad. Celia Euvaldo. São Paulo: Ubu Editora, 2017. 
FURLANETO, Audrey. "Paulo Nazareth, um artista exótico", O Globo, Rio de Janeiro, 26 out 2013. Disponível em <http://oglobo.globo.com/cultura/paulo-nazareth-um-artistaexotico-10544447>. Acessado em 10 fev. 2017.

GALEANO, Eduardo. As veias abertas da América Latina. Porto Alegre: L\&PM, 2016.

GARRAMUÑO, Florencia. Frutos estranhos: sobre a inespecificidade na estética contemporânea. Rio de Janeiro: Rocco, 2014.

HARTOG, François. Regimes de historicidade: presentismo e experiências do tempo. São Paulo, Autêntica, 2013.

HUYSSEN, Andreas. Culturas do passado-presente: modernismos, artes visuais, políticas da memória. Tradução Vera Ribeiro - 1. Ed. - Rio de Janeiro: Contraponto: Museu de Arte do Rio, 2014.

KIFFER, Ana. “A escrita fora de si”. In: Expansões contemporâneas: Literatura e outras formas. Orgs. Ana Kiffer e Florencia Garramuño. Belo Horizonte: Editora UFMG, 2014.

KRAUSS, Rosalind. A escultura no campo ampliado, Arte \& ensaios, vol. 17, 2008. pp. 128137. Disponível em http://www.ppgav.eba.ufrj.br/wpcontent/uploads/2012/01/ae17_Rosalind_Krauss.pdf. Acessado em 12 set. 2016.

. A Voyage to the North Sea - Art in the age of the post-medium condition, 1999. New York: Thames \& Hudson, 1999.

LUDMER, Josefina. Aqui América Latina - Uma especulação. Trad. Rômulo Monte Alto. Belo Horizonte: Editora UFMG, 2013.

. “Literaturas pós-autônomas”, trad. Flávia Cera, Sopro, n.20, jan. 2010.

MELENDI, María Angelica. “Aqui é arte: Paulo Nazareth”. In: Arte Contemporânea/LTDA. Rio de Janeiro: Cobogó, 2012.

. Estratégias da arte em uma era de catástrofes. Rio de Janeiro: Cobogó, 2017.

MELO, Janaina. “Caminhos e conversas de viagem”. In: Arte Contemporânea/LTDA. Rio de Janeiro: Cobogó, 2012.

MIGNOLO, Walter. "A colonialidade de cabo a rabo: o hemisfério ocidental no horizonte conceitual da modernidade”. In: LANDER, Edgardo (org). A colonialidade do saber: 
eurocentrismo e ciências sociais. Perspectivas latino-americanas. Buenos Aires: CLACSO, 2005 .

NAZARETH, Paulo. Arte contemporânea/LTDA. Rio de Janeiro: Cobogó, 2012.

NUNES, Hélio Alvarenga. "Sem essa de 'outro', Paulo Nazareth é nós". In: Arte Contemporânea/LTDA. Rio de Janeiro: Cobogó, 2012.

RUFFEL, Lionel. Brouhaha, Les mondes du contemporain. Paris : Verdier, 2016.

QUIJANO, Anibal. “Colonialidade do poder, eurocentrismo e América Latina”. In: LANDER, Edgardo (org). A colonialidade do saber: eurocentrismo e ciências sociais. Perspectivas latino-americanas. Buenos Aires: CLACSO, 2005.

SARLO, Beatriz. Tempo passado: cultura da memória e guinada subjetiva. São Paulo: Companhia das Letras, 2007.

SUSSEKIND, Flora. "Objetos verbais não-identificados”, O Globo, Rio de Janeiro, 21 set. 2013, Prosa \& Verso, pp. 4-5.

TAYLOR, Diana. O arquivo e o repertório: performance e memória cultural nas Américas. Trad. Eliana Lourenço de Lima Reis. Belo Horizonte: Editora UFGMG, 2013.

WARBURG, Aby. “Memórias da viagem à região dos índios Pueblos na América do Norte”. In: Histórias de fantasmas para gente grande: escritos, esboços e conferências. Org. Leopoldo Waizbort. Trad. Lenin Bicudo Bárbara. São Paulo: Cia das Letras, 2015.

ZYLBERKAN, Mariana. "Paulo Nazareth, o andarilho das artes", Veja.com, São Paulo, 26 mai. 2012. Disponível em <http://veja.abril.com.br/entretenimento/paulo-nazareth-oandarilho-das-artes/>. Acessado em 23 fev. 2017.

Recebido em: 02/03/2021 Aprovado em: 15/12/2021

Universidade do Estado de Santa Catarina - UDESC Centro de Ciências Humanas e da Educação - FAED

PerCursos

Volume 22 - Número 50 - Ano 2021 revistapercursos@gmail.com 